\title{
POLITICAS EDUCACIONAIS E FORMAÇÃO DE PROFESSORES: IMPACTO DAS PROPOSTAS CURRICULARES NOS CURSOS DE PEDAGOGIA DA UNOESC- SC NA VISÃO DOS DOCENTES
}

\author{
M.L.P. ALMEIDA ${ }^{1}$, J.T. SANTOS NETO ${ }^{2}$ \\ Universidade Estadual de Campinas ${ }^{1}$, Universidade do Oeste de Santa Catarina ${ }^{2}$ \\ malu04@uol.com.br ${ }^{1}$
}

Artigo submetido em 08/08/2016 e aceito em 24/06/2019

DOI: $10.15628 /$ holos.2019.4934

\section{RESUMO}

Fruto de pesquisa PIBIC - CNPq e vinculada à Rede Iberoamericana de Estudos e Pesquisas em Políticas e Processos de Educação Superior, em parceria com o GIEPES da UNICAMP, o texto apresenta os resultados parciais dos impactos das políticas curriculares na formação do pedagogo na visão dos docentes dos cursos de dois campi da UNOESC. Coletou os dados com o encuestafacil.com e usou a metodologia qualitativa/quantitativa, baseada na análise de conteúdo, via Lawrence Bardin. Dos entrevistados, a maioria tem consciência de que a matriz curricular forma o pedagogo para o mercado e não para o mundo do trabalho. A minoria sugere mudanças, refletindo sobre a autonomia intelectual e a conscientização de si, do outro e da classe, com conteúdo voltado para a emancipação da educação e não somente para a regulação da educação básica.

PALAVRAS-CHAVE: Políticas de Educação Superior, Políticas de Formação de professores, Pedagogia, Universidade e Formação de Professores.

\section{EDUCATIONAL POLICIES AND TEACHER TRAINING: PROPOSALS IMPACT OF CURRICULUM IN PEDAGOGY UNOESC- SC COURSES IN VISION OF TEACHERS.}

\begin{abstract}
Search result PIBIC - CNPq and linked to the Iberoamerican Network for Studies and Research in Policy and Higher Education Process, in partnership with the GIEPES UNICAMP, the text presents the partial results of the impact of curriculum policies in the formation of the pedagogue in the view of teachers the two campuses UNOESC courses. Collected data with encuestafacil.com and used the qualitative / quantitative methodology,
\end{abstract}

based on content analysis, via Lawrence Bardin. Of the respondents, most are aware that the curriculum form the pedagogue to the market and not to the world of work. Minority suggests changes, reflecting on the intellectual autonomy and awareness of itself and the other class, with content aimed at the emancipation of education, not only for the regulation of basic education.

KEYWORDS: Policies for Higher Education, Education Policy teachers, Education, University and Teacher Training. 


\section{INTRODUÇÃO}

Os cursos de formação de professores vêm sofrendo inúmeras transformações no que tange às novas exigências das leis e diretrizes curriculares, com propostas vão desde a reestruturação de cursos até a possibilidade do trabalho docente ser por competências. A ênfase da discussão tem estado centrada, em grande parte, na prática pedagógica dos professores e seus saberes.

$\mathrm{Na}$ verdade, ao falarmos sobre formação de professores, estamos trazendo para debate aspectos relacionados às licenciaturas, à concepção de educação, de ensino superior, aos saberes que constituem o magistério. Especificamente nessa proposta de investigação pretendemos deter a discussão sobre as Políticas de Educação Catarinense, mais especificamente as Curriculares associadas e inseridas na questão da formação. A partir desses fatores é que propomos investigar uma das formas de Políticas Educacionais que é a Política Curricular, e a maneira como são decididos colegiadamente os rumos da formação de professores, mais especificamente as Faculdades de Pedagogia frente aos diversos modos de regulação da universidade, como o estatal, o federal e o pretenso comunitário (representado nesta pesquisa pelas IES do Sistema ACAFE).

Assim, nossa proposta de investigação transita em analisar a partir das políticas curriculares catarinenses a formação de pedagogos dos cursos de Pedagogia dos campi de Capinzal e Campos Novos da UNOESC. O projeto que faz parte do GEPES UNICAMP e do GEPPES SUL está vinculado diretamente à Rede Ibero-americana de Pesquisas em Políticas e Processos em Educação Superior.

\section{SOBRE A UNOESC E O CURSO DE PEDAGOGIA}

A Unoesc surgiu no final da década de 60, em 1995 foi reconhecida como universidade pelo Conselho Estadual de Educação e, consequentemente, credenciada pelo Ministério da Educação. O Curso de Pedagogia da Unoesc tem suas raízes na década de 1970. Com o passar dos anos, o curso marcou significativamente a trajetória da instituição, além de estar presente em todos os campi da Unoesc. O Curso de Pedagogia no Campus Aproximado de Campos Novos iniciou em Janeiro de 1995, com funcionamento no antigo Seminário Paulo VI, sendo que de 1995 a 2000 a oferta era de Regime Especial de Férias com aulas nos meses de janeiro, fevereiro e julho.

A implantação do Curso de Pedagogia da Unidade de Capinzal foi motivada pela promulgação da LDBEN (9393/1996), que tornou obrigatório ao profissional da educação ter curso superior. A Secretaria Municipal de Educação da Capinzal, respaldada pela Câmara de Vereadores, na pessoa da professora Noemia Bonamigo Pizzamiglio, vereadora na época, elaborou o projeto de instalação da Unoesc em Capinzal. Em setembro de 1998, iniciaram as aulas do curso de Pedagogia, nos espaços da Escola Municipal Viver e Conhecer, coordenado pela professora Noemia Pizzamiglio. A Prefeitura cedeu o espaço da escola até o ano de 2004, quando foi inaugurado o prédio da Unoesc (UNOESC, 2016).

O Curso de Pedagogia da Unoesc tem suas raízes na década de 1970 . No ano de 2002, pelo Parecer no 93/CONSUN/2002 e Resolução no 117/CONSUN/2002, a Unoesc, Campus de Joaçaba, 
aprovou a reestruturação do projeto pedagógico do Curso de Pedagogia, buscando atender às mudanças anunciadas pelas Resoluções CNE/CP 1, de 18 de fevereiro de 2002 - que institui as diretrizes curriculares nacionais para a formação de professores da Educação Básica, em nível superior, curso de licenciatura e de graduação plena - e CNE/CP 2, de 19 de fevereiro de 2002, que instituiu a duração e carga horária dos cursos de licenciatura, de graduação plena, de formação de professores da Educação Básica em nível superior, alterando a matriz curricular, a concepção pedagógica, a metodologia de ensino e a modalidade de oferecimento. (UNOESC, 2015)

O Curso de Pedagogia no Campus Aproximado de Campos Novos iniciou em Janeiro de 1995 e em setembro de 1998 iniciaram as aulas do curso de Pedagogia de Capinzal, ambos os cursos passaram por processos de educação através de processo regime especial (aulas sexta-feira e sábado dia todo) e também processo de ensino regular, com aulas semanais. Os cursos pretendem formar profissionais que deverão apresentar a docência e a gestão escolar como elementos centrais a sua identidade profissional, indicando a construção de um perfil sustentado pela investigação, produção e disseminação do conhecimento sobre a organização escolar em sua complexidade, reconhecendo-se como profissional envolvido com uma educação crítica, transformadora e comprometida com a democratização do acesso aos conhecimentos produzidos historicamente pela humanidade. Cabendo ao Pedagogo da Unoesc exercer a docência na educação infantil e nos anos iniciais do ensino fundamental, bem como a gestão escolar e dos processos de ensino aprendizagem na escola envolvendo-se política e pedagogicamente com o planejamento, a execução e a avaliação das atividades educativas. (UNOESC, 2015)

\section{SOBRE A PESQUISA}

As questões submetidas foram as seguintes: a) Quais são as perspectivas de formação adotadas pelos docentes do curso de Pedagogia do campus Capinzal da UNOESC? b) Quais valores os docentes explicitam quanto ao que é, e ao que deve ser o currículo do curso? c) Há diferença entre aquilo que os docentes valorizam como formação e aquilo que percebem estar sendo desenvolvido pelo currículo? d) É possível a formulação de novas estruturações para a questão curricular do curso de Pedagogia do campus de Capinzal?

A metodologia utilizada foi a qualitativa/quantitativa.

A coleta de dados da pesquisa deu-se através do programa Encuestafacil.com, uma ferramenta de pesquisas online de bastante influência na Europa e na América Latina. Foram convidados 61 docentes de Capinzal e Campos Novos para que respondessem ao questionário; destes, $44(72,13 \%)$ docentes visualizaram a pesquisa e $26(42,62 \%)$ responderam. Utilizamos um questionário para coleta de dados com oito questões (sete objetivas e uma descritiva), sendo que a penúltima questão contou com 45 alternativas a serem respondidas escolhendo: Concordo plenamente, concordo parcialmente, não tenho opinião, discordo plenamente, discordo parcialmente.

\section{RESULTADOS DA PESQUISA}


Os 61 docentes dos campi de Campos Novos e Capinzal foram convidados por meio eletrônico. Os primeiros convites aconteceram no dia 24 de novembro de 2015, porém como não obtivemos um número relevante de respostas. Refizemos o convite no dia 02 de fevereiro de 2016, quando enviamos aos 61 professores dois e-mails para que participassem da pesquisa, num total de 122 correspondências eletrônicas. Desta feita, 44 visualizaram mas não responderam e 26 visualizaram e responderam. Sobre o perfil dos respondentes, apuramos que 22 são mulheres (85\%) e quatro são homens (15\%). A faixa etária apresenta-se desta forma: 20 a 30 anos (dois respondentes - 8\%); 30 a 40 anos (seis docentes - 23\%); e mais de 40 anos (18 participantes - 69\%). Sobre o estado civil, 13 informaram estar casados (50\%), cinco se dizem solteiros (19\%), quatro são divorciados (15\%) e outros quatro possuem uma união estável (15\%). Com relação a filhos, seis responderam que não possuem (23\%), nove disseram ter um filho (35\%), 10 informaram possuir dois filhos (38\%) e um docente disse ter três filhos. Sobre o ano de conclusão do curso, 17 responderam que concluíram em 2009 (68\%), três informaram o ano de 2010 (11\%), três disseram que foi em 2011 (11\%), três em 2014 (11\%) e uma pessoa não respondeu.

Quanto à realização de algum curso após a conclusão da graduação, seis docentes (23\%) responderam que realizaram curso de capacitação, 15 informaram que fizeram especialização (58\%), 17 fizeram mestrado (65\%), cinco concluíram doutorado (19\%), e cinco (19\%) realizaram outros tipos de cursos, porém não especificaram quais.

Na sequência, os docentes optaram pelas competências que acreditam ser componentes o currículo da universidade do século XXI. Assim, de acordo com os entrevistados, o currículo deve...

1. Favorecer a aquisição de conhecimentos gerais: 17 docentes concordam totalmente (65\%), oito concordam parcialmente (31\%) e um discorda parcialmente (4\%);

2. Favorecer a aquisição de conhecimentos específicos: 16 entrevistados concordam totalmente (62\%), oito concordam parcialmente (31\%) e dois discordam parcialmente (8\%);

3. Proporcionar cultura geral e conhecimento especializado de forma complementar: 14 respondentes concordam totalmente (54\%), 10 concordam parcialmente $(38 \%)$ e dois discordam parcialmente (8\%);

4. Desenvolver habilidades de pesquisa: 21 afirmam que concordam totalmente (81\%), quatro concordam parcialmente (15\%) e um discorda parcialmente (4\%);

5. Desenvolver um saber integrando conhecimentos de diferentes áreas: 22 concordam totalmente (85\%), e quatro concordam parcialmente (15\%);

6. Trabalhar o conteúdo teórico relacionado com a prática: 23 docentes concordam totalmente (86\%), dois concordam parcialmente (8\%) e um discorda plenamente (4\%);

7. Desenvolver a criatividade do aluno: 23 concordam totalmente ( $88 \%$ ) e três concordam parcialmente (12\%);

8. Atentar às demandas do mercado: quatro concordam totalmente (15\%), 13 concordam parcialmente $(50 \%)$, cinco discordam plenamente $(19 \%)$ e quatro discordam parcialmente (15\%);

9. Priorizar as necessidades sociais: 10 entrevistados concordam totalmente (38\%), 13 concordam parcialmente (50\%), um discorda plenamente (4\%) e dois discordam parcialmente (8\%); 
10. Desenvolver a capacidade de buscar, selecionar e relacionar informações: 24 concordam totalmente (92\%), um concorda parcialmente (4\%) e um discorda plenamente (4\%);

11. Organizar disciplinas de forma linear e sequenciada: dois concordam totalmente (8\%), 10 concordam parcialmente (38\%), um não tem opinião sobre o assunto (4\%), 10 discordam plenamente (38\%) e três discordam parcialmente (12\%);

12. Superar a fragmentação do conhecimento na organização: 21 concordam totalmente (81\%) e cinco concordam parcialmente (19\%);

13. Enfatizar uma formação pragmática visando a atuação profissional: dois concordam totalmente (8\%), 12 concordam parcialmente (46\%), cinco discordam plenamente (19\%) e sete discordam parcialmente (27\%);

14. Enfatizar o trabalho colaborativo: 17 concordam totalmente (65\%), oito concordam parcialmente (31\%) e um discorda parcialmente (4\%);

15. Priorizar a dimensão ética na formação profissional: 24 docentes concordam totalmente (92\%) e dois concordam parcialmente (8\%);

16. Priorizar a dimensão técnica na formação profissional: 4 concordam totalmente (15\%), 10 concordam parcialmente (38\%), quatro discordam plenamente (15\%) e oito discordam parcialmente (31\%);

17. Contribuir para o autoconhecimento (das características e potencialidades pessoais): 21 concordam totalmente (81\%), quatro concordam parcialmente (15\%) e um discorda parcialmente (4\%);

18. Desenvolver o pensamento investigativo: 23 concordam totalmente $(88 \%)$ e três concordam parcialmente (12\%);

19. Garantir a interdisciplinaridade entre os conteúdos trabalhados: 22 docentes concordam totalmente (85\%) e quatro concordam parcialmente (15\%);

20. Desenvolver o espírito de solidariedade: 21 concordam totalmente (81\%), três concordam parcialmente (12\%), um discorda plenamente (4\%) e um discorda parcialmente (4\%);

21. Desenvolver o espírito competitivo: 3 concordam totalmente (12\%), seis concordam parcialmente (23\%), um não tem opinião formada (4\%), nove discordam plenamente (35\%) e sete discordam parcialmente (27\%);

22. Preparar com uma visão exclusiva para o mercado: cinco concordam totalmente (19\%), quatro concordam parcialmente (15\%), 12 discordam plenamente (representando 45\%) e cinco discordam parcialmente (19\%);

23. Enfatizar uma formação mais geral e ampla: 11 concordam totalmente (42\%), 12 concordam parcialmente (46\%), dois discordam plenamente (8\%) e um discorda parcialmente (4\%);

24. Incentivas a autonomia na busca de conhecimentos: 24 concordam totalmente (92\%) e dois concordam parcialmente (8\%);

25. Desenvolver uma formação geral que seja a base da formação específica: 17 concordam totalmente $(65 \%)$, sete concordam parcialmente (27\%), um discorda plenamente (4\%) e um discorda parcialmente (4\%); 
26. Concentrar-se na formação especializada: quatro concordam totalmente (15\%), 14 concordam parcialmente (54\%), três discordam plenamente (12\%) e cinco discordam parcialmente (19\%);

27. Buscar solucionar os problemas sociais e humanos: 20 concordam totalmente $(77 \%)$, quatro concordam parcialmente (15\%) e dois discordam plenamente $(8 \%)$;

28. Visar apenas o desenvolvimento técnico e profissional: três concordam totalmente (15\%), cinco concordam parcialmente (19\%), um não tem opinião sobre o assunto (4\%), 12 discordam plenamente (46\%) e cinco discordam parcialmente (19\%);

29. Desenvolver apenas as disciplinas de valor utilitarista: dois concordam totalmente (8\%), quatro concordam parcialmente (15\%), 15 discordam plenamente (58\%) e cinco discordam parcialmente (19\%);

30. Dar prioridade para o treinamento profissional: dois docentes concordam totalmente (8\%), 10 concordam parcialmente (38\%), 10 discordam plenamente (38\%) e quatro discordam parcialmente (15\%);

31. Dar mais cultura geral e menos treinamento técnico-profissional: quatro concordam totalmente (15\%), 15 concordam parcialmente (58\%), quatro discordam plenamente (15\%) e três discordam parcialmente (12\%);

32. Desenvolver os aspectos afetivo-emocionais: 18 concordam totalmente (69\%), cinco concordam parcialmente (19\%) e três discordam parcialmente (31\%);

33. Desenvolver argumentação e julgamentos embasados cientificamente: 23 concordam totalmente (88\%) e três concordam parcialmente (12\%);

34. Desenvolver atitudes que favoreçam o trabalho em equipe multidisciplinar: 22 concordam totalmente (85\%) e quatro concordam parcialmente $(15 \%)$;

35. Desenvolver a capacidade de se comunicar: 23 concordam totalmente (88\%) e três concordam parcialmente (12\%);

36. Capacitar para resolver os problemas com visão técnica: dois concordam totalmente ( 8 $\%)$, seis concordam parcialmente (23\%), 10 discordam plenamente (38\%) e oito discordam parcialmente (31\%);

37. Capacitar para resolver os problemas com visão social: 15 concordam totalmente $(58 \%)$, nove concordam parcialmente (35\%), um discorda plenamente (4\%) e um discorda parcialmente (4\%);

38. Orientar as pesquisas científicas para que tenham mais valor social: 21 concordam totalmente (81\%) e cinco concordam parcialmente (19\%);

39. Orientar as pesquisas para que tenham mais valor para o mercado: sete concordam totalmente $(27 \%), 11$ concordam parcialmente $(42 \%)$, cinco discordam plenamente (19\%) e três discordam parcialmente (12\%);

40. Desenvolver apenas o conhecimento específico da área: um concorda totalmente (4\%), três concordam parcialmente (12\%), um não tem opinião formada (4\%) 14 discordam plenamente (54\%) e sete discordam parcialmente (27\%);

41. Desenvolver a capacidade de analisar os mais diversos aspectos de uma situaçãoproblema: 24 concordam totalmente (92\%), um concorda parcialmente $(4 \%)$ e um discorda plenamente (4\%); 
42. Conscientizar sobre os impactos da atuação de sua área profissional no meio ambiente: 19 concordam totalmente (73\%), cinco concordam parcialmente (19\%) e dois discordam parcialmente (8\%);

43. Trabalhar inovações tecnológicas para o mercado: 15 entrevistados concordam totalmente (58\%), sete concordam parcialmente (representando $27 \%)$, dois discordam plenamente (8\%) e oito discordam parcialmente (8\%).

Os principais comentários feitos pelos docentes ao responderam à pesquisa foram: "Pesquisa importante"; "Ano de conclusão antes de 2009"; "Questionário muito interessante"; "Boa pesquisa, o currículo deve primordialmente ser revisto, repensado e condicionado a uma vida mais "humana'".

\section{CONSIDERAÇÕES FINAIS}

A pesquisa levanta, assim como as outras já comentadas, que as políticas e práticas pertinentes à formação do professor para educação básica necessitam urgente de uma reforma, considerando-se as profundas mudanças da sociedade.

Pereira (1999), apresenta alguns modelos de formação docente, e discute as características de cada uma, como o modelo da racionalidade técnica, que o professor é visto como um técnico que aplica as regras que derivam do conhecimento científico e do conhecimento pedagógico. Conforme o autor, este modelo "mostra-se inadequado à realidade da prática profissional docente" (PEREIRA, 1999, p.112), sendo este modelo o mais identificado em cursos de Licenciaturas em instituições particulares e faculdades isoladas.

Outro modelo é o de racionalidade prática, onde o professor é considerado um profissional autônomo, que decide e cria suas próprias ações pedagógicas. Este modelo considera que a prática não é o locus da aplicação de um conhecimento científico e pedagógico, mas um espaço para reflexão e criação.

Pode-se neste sentido propor um terceiro modelo, onde a prática é entendida como eixo para preparação do professor. Mas expõe que este modelo também possui várias fragilidades, como o cuidado no planejamento e na intencionalidade das atividades e cargas horárias destas práticas, ou, o descuido com o embasamento teórico na formação.

Pereira (1999) apresenta uma alternativa discutida em eventos na Universidade Federal de Minas Gerais, onde a pesquisa deve ser a protagonista da formação docente, juntamente com a formação inicial e a formação continuada. Defende que estas ações irão desenvolver uma outra cultura institucional dos cursos de formação de professores, de maneira mais qualitativa, a fim de debaterem sobre os desafios propostos pela nova conjuntura política e sociocultural brasileira, em um processo de construção do conhecimento.

Neste estudo, a inserção da discussão sobre o Estado é necessária, pois como apresentado, este exerce diretamente funções econômicas e ideológicas. Diante do explanado, é perceptível que vivemos em uma sociedade regulada e praticamente sem classes, pois o Estado é um representante manipulado da classe dominante. Na situação atual posta, o capital monopoliza a 
cultura, ciência, arte, Universidade, intelectuais, pesquisa, onde o cenário deveria ser contrário, a Universidade revolucionária e independente.

A Universidade tem por papel ético poder construir conhecimentos que possibilitem uma discussão entre as estruturas, setores, e que contribua com conhecimentos independentes e não influenciados, sem tendências de mercado ou interesses. Assim, "as investigações das políticas educacionais não podem ser dissociadas do estudo sobre o Estado". (ALMEIDA, 2015, p. 39)

\section{REFERÊNCIAS}

ALMEIDA, M. L. P. (2013, out). Políticas de Educação e Estado Avaliador na América Latina: uma análise para além das avaliações externas. Madrid: REICE - Revista Ibero Americana sobre Calidad, Eficacia y Cambio em Educación, 11(4), p. 77-91, out. 2013. disponível em: <http://www.rinace.net/reice/numeros/arts/vol11num4/art5.pdf> Acesso em: 24 de ago. 2015.

ALMEIDA, M. L. P., TELLO, C. (2013). Estudos Epistemológicos no campo da pesquisa em Política Educacional. Campinas, SP: Mercado das Letras.

BRASIL. Ministério da Educação e Cultura. (1996). Lei de Diretrizes e Bases da Educação Nacional: n. 9394/96. Brasília: MEC.

FREITAS, H. C. L. (2007). A (nova) política de formação de professores: a prioridade postergada. Campinas: Unicamp - Educação \& Sociedade, 28(100) Especial, p. 1203-1230, out. Disponível em: < www.scielo.br/pdf/es/v28n100/a2628100.pdf> Acesso em: 29 de nov. 2015.

UNOESC. Disponível em: http://www.unoesc.edu.br/noticias/single/nova-turma-da-uniti-teminicio-em-capinzal Acesso em: 28 de novembro de 2015

UNOESC. Disponível em: http://www.unoesc.edu.br/unoesc/conheca-unoesc-single/capinzal Acesso em: 28 de novembro de 2015

UNOESC. Disponível em: http://www.unoesc.edu.br/unoesc/conheca-unoesc-single/camposnovos Acesso em: 28 de novembro de 2015 